\title{
The ALR-RSI score is a valid and reproducible scale to assess psychological readiness before returning to sport after modified Broström-Gould procedure
}

\author{
Charles Pioger ${ }^{1}$ (D) Stéphane Guillo ${ }^{2}$. Pierre-Alban Bouché ${ }^{3} \cdot$ François Sigonney $^{1} \cdot$ Marc Elkaïm $^{4} \cdot$ Thomas Bauer $^{1}$. \\ Alexandre Hardy ${ }^{5}$
}

Received: 29 November 2021 / Accepted: 13 January 2022 / Published online: 25 January 2022

(c) The Author(s) 2022, corrected publication 2022

\begin{abstract}
Purpose Psychological readiness scores have been developed to optimize the return to play in many sports-related injuries. The purpose of this study was to statistically validate the ankle ligament reconstruction-return to sport injury (ALR-RSI) scale after modified Broström-Gould (MBG) procedure.

Methods A similar version of the ACL-RSI scale with 12 items was adapted to quantify the psychological readiness to RTS after MBG and to describe construct validity, discriminant validity, feasibility, reliability and internal consistency of the scale, according to the COSMIN methodology. The term "knee" was replaced by "ankle". The AOFAS and Karlsson scores were used as references patient-related outcome measurements (PROMs).

Results A total of 71 patients were included. The ALR-RSI score after MBG procedure was highly $(r>0.5)$ correlated to the AOFAS and Karlsson scores, with a Pearson coefficient $r=0.69$ [0.54-0.80] and 0.72 [0.53-0.82], respectively. The mean ALR-RSI score was significantly greater in the subgroup of 55 patients who resumed sports activity compared to those that no longer practiced sport: $61.9(43.8-79.6)$ vs 43.4 (25.0-55.6), $(p=0.01)$. The test-retest showed an "excellent" reproducibility with a $\rho$ intraclass correlation coefficient of 0.93 [0.86-0.96]. The Cronbach's alpha statistic was 0.95 , attesting an "excellent" internal consistency between the 12 ALR-RSI items.

Conclusion The ALR-RSI score is a valid and reproducible tool for the assessment of psychological readiness to RTS after an MBG procedure for the management of CLAI, in a young and active population. The ALR-RSI score may help to identify and counsel athletes on their ability to return to sport.
\end{abstract}

Level of evidence III.

Keywords ALR-RSI · Ankle $\cdot$ Modified Broström-Gould $\cdot$ Psychological $\cdot$ Return to sport

Charles Pioger

charlespioger@gmail.com

1 Department of Orthopaedic Surgery, Ambroise Paré Hospital, Paris Saclay University, 9, Avenue Charles de Gaulle, 92100 Boulogne-Billancourt, France

2 Center for Orthopaedic Sports Surgery, Bordeaux-Mérignac, France

3 Department of Orthopaedic Surgery, Lariboisière Hospital, Paris University, Paris, France

4 Clinique de Tournan, Tournan-en-Brie, France

5 Ramsay Santé, Clinique du Sport Paris V, Paris, France

\section{Introduction}

Inversion ankle trauma is one of the most frequently sportsrelated injury and usually involves partial or complete rupture of the anterior talofibular ligament (ATFL) [7, 12, 29]. Conservative treatment and functional rehabilitation remain the standard management for acute ankle sprains, with satisfactory outcomes [24], but controversy persists about the prevention of ankle sprain recurrence [11]. There are a still number of patients who experience ankle swelling, pain and/or a feeling of instability [25, 36]. Among them, $>20 \%$ experience chronic lateral ankle instability (CLAI), defined as recurrent acute sprain, giving way of the ankle with a perception of an insecure ankle by the patient, and avoidance/adaptation of sport activities, for at least 1 year [9, 29]. This instability can lead 
to cartilage damage [30], kinematic disorders [4] and early osteoarthritis of the ankle [32]. Surgery should be considered for patients with sporting demands and symptomatic ankle instability.

The modified Broström-Gould procedure (MBG) remains the gold standard for the management of CLAI and consists in the association of the ATFL repair (retention and direct suture) and the transfer of the extensor retinaculum [6, 16, 29]. The all-arthroscopic approach is increasingly used, to assess and address any associated intra-articular lesions with reduced morbidity for the patient $[19,21,37]$.

In a young and active population who underwent anatomic repair surgery, one of their expectations is the ability to resume sports activity and patients are usually anxious to know the achievable level of play. Although the MBG is safe and allows most patients to resume preinjury sports activities, it has been reported that around $25 \%$ are unable to return to sport (RTS) [18, 21]. Some reports suggest that physical impairments are not sufficient to explain these low RTS rates following sport-related injuries and highlighted the role of psychological factors in the RTS process [1,23]. The assessment of the motivation, self-confidence in performance and fear remains a key element to take into account before resuming sport activities. Therefore, psychological measurements scales have been developed to optimize the RTS rate and reduce the risk of surgical failure in many athletic injuries. In particular, Webster et al. [33] designed a scale of 12 items in patients following anterior cruciate ligament reconstruction (ACLR) to assess their psychological readiness to resume sports. This was followed by the development of numerous psychological assessment scales for return to sport after sport-related injuries, including shoulder instability (SIRSI) [8], hip arthroscopy with femoroacetabular impingement (FAI) syndrome (HipRSI) [35] or ankle ligament reconstruction (ALR-RSI) [28]. To date, no tool exists to analyze the psychological readiness after MBG procedure.

The main purpose of this study was to statistically validate the ankle ligament reconstruction-return to sport injury (ALRRSI) scale using a population of patients who underwent an MBG surgery. A similar version of the ACL-RSI scale with 12 items was adapted to quantify the psychological readiness to RTS after MBG and to describe construct validity, discriminant validity, feasibility, reliability and internal consistency of the scale. Physicians and patients could use this tool to ensure psychological readiness to return to sport after MBG procedure.

\section{Materials and methods}

\section{Study design}

Institutional review board approval (COSRGDS-2021-06-003) was granted for the study and all patients provided informed consent to participate.

This study identified and enrolled patients who underwent ankle ligament repair for the treatment of CLAI, in 2018 and 2019 via database of three surgical units by searching for relevant diagnostic codes. From this group, inclusion criteria comprised the following: minimum follow-up of 2 years, $>18$ years old, sport activity prior to surgery and no associated lesion during the procedure. An all inside endoscopic MBG procedure was performed in all cases [10].

\section{ALR-RSI scale}

The ALR-RSI was similar of the scale validated for the ankle ligament reconstruction and adapted from the ACLRSI score [2]. The word "knee" was replaced by "ankle". It contains 12 items thought to capture the psychological readiness before RTS and include: emotions ( 5 items), confidence in performance (5 items) and risk evaluation ( 2 items). The total score was equal to the sum of the 12 answers and divided by 1.2 to obtain a percentage. The score scale goes from 0 (lowest psychological readiness) to 100 (highest psychological readiness).

The last version of the ALR-RSI was validated following the international Consensus-based Standards for the selection of health status Measurement Instruments (COSMIN) guidelines [20]. An additional and standardized questionnaire was designed to capture demographic data and to collect two valid and reliable functional scores. The references PROMs used were the Karlsson score [26] and the American Orthopedic Foot and Ankle Society (AOFAS) score [15].

A total of 71 patients responded to a questionnaire including the ALR-RSI scale, the Karlsson score and the AOFAS score. Participants were also asked to give consent and to complete components relating to their return to sport. The ALR-RSI was completed twice at 15-day interval.

\section{Statistical analysis}

To describe quantitative variables, the mean and standard deviation (SD) were used. To describe dichotomous variables, the number of events and their percentage were used. A sample size of 71 produces a two-sided $95 \%$ confidence interval with a width smaller than 0.24 when the estimate of Spearman's rank correlation is above 0.75 . To estimate the correlations between ALR-RSI, the total Karlsson 
score and the AOFAS, Spearman coefficients were used. If the coefficient was $r>0.5$, the correlation was considered as "strong", "moderate" if $0.5<r<0.3$ and "weak" if $0.3<r<0.1$. A Wilcoxon test was used to compare the "patient" and "control" groups to assess the discriminant validity. We also compared the patients who resumed sport and those who had abandon their sport activity. The Cronbach alpha coefficient was calculated to estimate the internal consistency and was "excellent" if $\alpha \geq 0.90$. The $\rho$ intraclass correlation coefficient (ICCC) was used to evaluate the reliability. The reproducibility was "excellent" $(\rho>0.75)$ or "good" $(0.75<\rho<0.40)$. The percentage of missing responses, the ceiling and floor effects allowed to evaluate the feasibility [31]. The statistical analyses were performed using the R software (version 3.5).

\section{Results}

A total of 71 patients completed the survey and were included in the study. Each had undergone an ankle ligament repair with an all inside endoscopic MBG procedure.

Of these 71 cases, only two were professional athletes (2.8\%), whereas 25 practiced sport activity in competition (35.2\%), 33 as recreational and regular practice (46.5\%) and 11 as occasional practice $(15.5 \%)$. The main scores outcomes and the distribution of sports commonly practiced by the study population are summarized in Table 1 .

\section{Psychometric analysis}

\section{Convergent and structural validity (Tables 2, 3)}

The ALR-RSI scale was highly $(r>0.5)$ and significantly correlated to the reference PROMs with a Pearson correlation coefficient $r=0.69$ [0.54-0.80] regarding the Karlsson score and $r=0.72$ [0.53-0.82] for the AOFAS. Also, the ALR-RSI scores of RTS subgroup were found discriminant. The mean ALR-RSI score was significantly higher among the 55 patients who resumed sports activity compared to those that no longer practiced sport: 61.9 (43.8-79.6) vs 43.4 (25.0-55.6), $(p=0.01)$.

\section{Feasibility}

No item of the ALR-RSI was missed. The floor effect, defined as the proportion of patients with the minimum score, ranged from 0 to $1.7 \%$, and the ceiling effect relating to the highest score ranged from 4.2 to $35.2 \%$.
Table 1 Baseline characteristics

\begin{tabular}{|c|c|c|c|}
\hline Parameters & Values & $N$ & Statistics \\
\hline \multirow[t]{2}{*}{ Gender } & Female & 35 & $49.3 \%$ \\
\hline & Male & 36 & $50.7 \%$ \\
\hline Follow-up (years) & & 71 & $2.6(2.0 ; 3.7)$ \\
\hline ALR-RSI total & & 71 & $58.3[41.3 ; 77.5]$ \\
\hline Karlsson total & & 71 & $83.3[74.7 ; 88.7]$ \\
\hline AOFAS total & & 71 & $85.0[74.0 ; 91.0]$ \\
\hline \multirow[t]{2}{*}{ Sport recovery } & No & 16 & $22.5 \%$ \\
\hline & Yes & 55 & $77.5 \%$ \\
\hline \multirow[t]{3}{*}{ If yes } & Sport change & 15 & $27.3 \%$ \\
\hline & Same sport, inferior level & 19 & $34.5 \%$ \\
\hline & Same sport, same level & 21 & $38.2 \%$ \\
\hline \multirow[t]{4}{*}{ Sport level } & Competition & 25 & $35.2 \%$ \\
\hline & Casual leisure level & 11 & $15.5 \%$ \\
\hline & Regular leisure level & 33 & $46.5 \%$ \\
\hline & Professional & 2 & $2.8 \%$ \\
\hline \multirow[t]{17}{*}{ Sport } & Athletics & 1 & $1.4 \%$ \\
\hline & Rowing & 1 & $1.4 \%$ \\
\hline & Badminton & 2 & $2.8 \%$ \\
\hline & Basketball & 6 & $8.5 \%$ \\
\hline & Running & 10 & $14.1 \%$ \\
\hline & Dance & 2 & $2.8 \%$ \\
\hline & Climbing & 1 & $1.4 \%$ \\
\hline & Soccer & 20 & $28.2 \%$ \\
\hline & Gymnastic & 2 & $2.8 \%$ \\
\hline & Handball & 6 & $8.5 \%$ \\
\hline & Struggle & 1 & $1.4 \%$ \\
\hline & Walking & 4 & $5.6 \%$ \\
\hline & Motocross & 1 & $1.4 \%$ \\
\hline & Bodybuilding & 3 & $4.2 \%$ \\
\hline & Swimming & 3 & $4.2 \%$ \\
\hline & Rugby & 6 & $8.5 \%$ \\
\hline & Squash & 2 & $2.8 \%$ \\
\hline
\end{tabular}

\section{Reliability (Fig. 1; Table 4)}

The reliability of the ALR-RSI score was explored from the calculation of the $\rho$ intraclass correlation coefficient (ICCC). In the current study, the $\rho$ intraclass correlation coefficient (ICCC) was found to be 0.93 [0.86-0.96], reflecting a reproducibility that was considered "excellent". In addition, the mean ALR-RSI score was 58.3 (41.2-77.5) at the first survey completion and $59.19(37.5-80.4)$ the second time.

\section{Internal consistency}

The Cronbach's alpha statistic for the ALR-RSI after MBG procedure was 0.95 , attesting an "excellent" internal consistency between the 12 ALR-RSI items. 
Table 2 Correlation between the ALR-RSI score and the Karlsson score

\begin{tabular}{lllrrrrr}
\hline Coefficient & ALR-RSI (/100) & \multicolumn{1}{l}{$\begin{array}{l}\text { Karlsson total } \\
(/ 100)\end{array}$} & Pain (/36) & \multicolumn{1}{l}{$\begin{array}{l}\text { Other symptoms } \\
(/ 28)\end{array}$} & \multicolumn{1}{l}{ ADL (/68) } & \multicolumn{1}{l}{ Sport (/20) } & ARQL (/16) \\
\hline \multirow{2}{*}{ Spearman } & $58.3[41.3-77.5]$ & $83.33[74.7-88.7]$ & $32[27.0-34.0]$ & $17[15.0-19.0]$ & $67[60.5-68.0]$ & $16[12.5-18.5]$ & $10[7.0-13.0]$ \\
& & $0.69[0.54-0.80]$ & $0.54[0.34-0.71]$ & $0.20[0.03-0.41]$ & $0.47[0.27-0.65]$ & $0.61[0.44-0.74]$ & $0.82[0.72-0.89]$ \\
\hline
\end{tabular}

Table 3 Correlation between the ALR-RSI score and the AOFAS score

\begin{tabular}{lll}
\hline Coefficient & ALR-RSI (/100) & AOFAS total (/100) \\
\hline & $58.3[41.3-77.5]$ & $85.0[74.0-91.0]$ \\
Spearman & & $0.72[0.53-0.82]$ \\
\hline
\end{tabular}

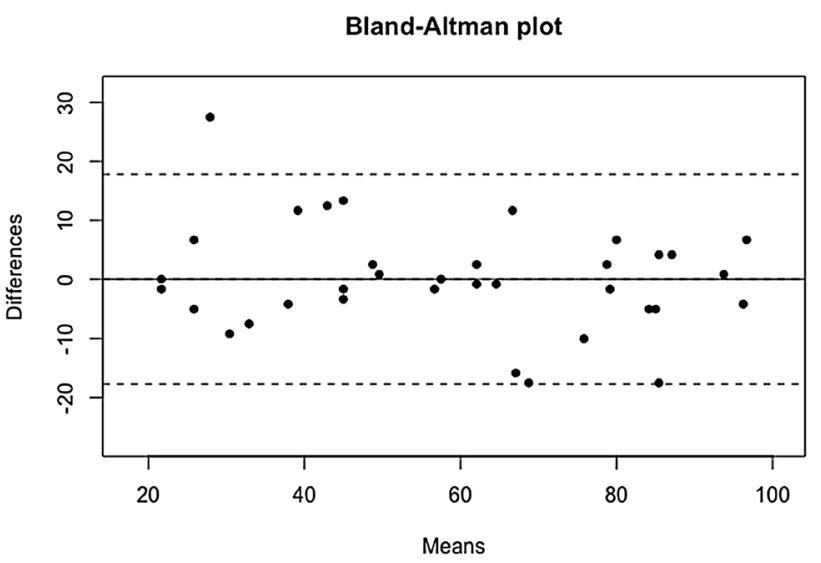

Fig. 1 Reproducibility of the ALR-RSI score with the test-retest: Bland-Altman plot

Table 4 Reproducibility of the ALR-RSI with the test-retest

\begin{tabular}{lll}
\hline Coefficient & ALR-RSI 1 (/100) & ALR-RSI 2 (/100) \\
\hline & $58.3[41.3-77.5]$ & $59.2(37.5-80.4)$ \\
ICC & & $\rho=0.93[0.86-0.96]$ \\
\hline
\end{tabular}

\section{RTS at a minimum 2-year follow-up}

Fifty-five participants (77.5\%) returned to sport after MBG procedure. In this group, patients resumed to the same sport with the preinjury level in 21 cases (38.2\%) and at a lower performance level in 19 cases (34.5\%). Sports practice was modified in 15 patients (27.3\%).

\section{Discussion}

The main finding of this study was the ALR-RSI score is a valid and reproducible tool for the assessment of psychological readiness to RTS after an MBG procedure for the management of CLAI, in a young and active population.

In the current study, $77.5 \%$ of patients returned to sport after MBG surgery, with a median follow-up of 2.6 years $(2.0 ; 3.7)$. Previous literature supports this finding. In particular, a prospective study conducted by the French Arthroscopic Society observed an RTS rate around $90 \%$ following arthroscopic repair for CLAI in recreational athletes and 73\% in competitive athletes. Regarding the RTS at the preinjury level, Maffulli et al. [18] presented long-term outcomes ( 8.7 years) about 42 athletes who underwent arthroscopic anterior talofibular Broström repair. In this cohort, the authors reported that 22 patients (58\%) resumed sports at their preinjury performance level, while six changed to less demanding sports and ten patients had to abandon their sport activity. Similar outcomes were observed by Nery et al. [21] following MBG procedure at an average follow-up of 10-year follow-up. More recently, Feng et al. [6] compared outcomes between arthroscopic MBG procedure with and without repair of the ATFL remnant. No difference was found in terms of ankle function or RTS rate between the repair and non-repair group at a minimum 2-year follow-up. In particular, around $70 \%$ of patients resumed sports at their previous level in both groups. In a retrospective case series, Park et al. [22] confirmed that the absence of remnant does not affect functional outcomes. Therefore, the ALR-RSI could be used in the MBG procedure for CLAI, regardless the repair of ATFL. In a retrospective study, Lee et al. [17] focused their research on 18 elite athletes who underwent MBG operation for CLAI. The return to play (RTP) rate was $83.3 \% 4$ months after the index surgery and $100 \%$ at 7 months. All pro athletes returned to their preinjury level. These excellent outcomes may be related to greater motivation often reported in pro athletes [3] but also to better access to professional monitoring and high-level rehabilitation. However, this report must be interpreted with cautious given the small number of patients in the cohort $(n=18)$.

The RTP timeline and the ability to resume sport at the preinjury level are primarily of concern for young and sportive population. White et al. [34] reported a lack of documented data to guide athletes in their RTP timeline. This is 
why, authors of further studies about surgical management of CLAI have to endeavor to track patients' progression during rehabilitation and report complete data about RTP, including psychological readiness. To date, recommendation for RTS criteria mainly includes clinical indicators such as joint stability, muscle strength and full ROM [29]. In a recent systematic review, Hunt et al. [13] highlighted the heterogeneity and the deficiency of consistent metrics for RTS in the included studies. The authors call for standardized, valid and reproducible tools for reporting RTS. In the same way, Clanton et al. [5] pointed out the need for subjective data to determine the ability to resume sports. To this end, the ALR-RSI scale should be used in routine, because functional testing coupled with psychological assessment allows taking RTS decisions safely. The ACL-RSI score remains an example of the interest of a psychological RTS evaluation after surgery. A strong and significant correlation between this psychological scale and return to sport has been demonstrated [27].

The choice of a survey with numeric answers allows simplifying the collect of data, compared to open questionnaire. Sports surgeons and physicians can easily refer to this questionnaire to counsel patients on RTS. However, Webster and Feller examined the responsiveness of the ACL-RSI score and found a moderate responsiveness over 6 months, using anchor-based methods. Specifically, the authors showed that the ACL-RSI scale had a sufficient responsiveness to detect clinical relevant changes at a group level and was more limited at an individual level.

There are several limitations in the current study. First, a possible selection bias may have been introduced, related to the inherent nature of a retrospective study. Second, the ALR-RSI scale was initially based on a modification of the ACL-RSI score and not developed for CLAI. However, the ALR-RSI has recently been validated for ankle instability after anatomic ligament reconstruction [28]. Moreover, many psychological assessment scores after sport-related injuries have been based on the ACL-RSI scale, which has been shown to be easily transferable to other joints and pathologies [8, 14, 35].

This study validated the ALR-RSI score as a routine practice tool to assess the psychological readiness to RTS after Broström procedure in patients with CLAI.

\section{Conclusion}

Through the results of this cohort, the ALR-RSI has to be considered as RTS metric tool to provide a clear message to patients who underwent MBG procedure for CLAI. Orthopaedic surgeons may use these findings to counsel and set expectations with their active patients, using evidence-based medicine on their ability to return to their favorite sport.
Supplementary Information The online version contains supplementary material available at https://doi.org/10.1007/s00167-022-06895-7.

Acknowledgements None.

Author contributions $\mathrm{CP}$ and $\mathrm{AH}$ have made substantial contributions to conception, study design, acquisition/interpretation of data, and in drafting the manuscript. FS have made substantial contributions to acquisition of data. PAB was in charge of the statistical analysis. TB, $\mathrm{ME}$, and SG have been involved in drafting or revising the manuscript critically. Each author has given final approval of the version to be published and agrees to be accountable for all aspects of the work in ensuring that questions related to the accuracy or integrity of any part of the work are appropriately investigated and resolved.

Funding No benefits in any form have been received or will be received related directly or indirectly to the subject of this article.

\section{Declarations}

Conflict of interest TB is educational consultant for Arthrex. CP, SG, $\mathrm{PAB}, \mathrm{FS}, \mathrm{ME}$ and $\mathrm{AH}$ have nothing to disclose.

Ethical approval Institutional review board approval (COSRGDS-2021-06-003) was granted for the study and all patients provided informed consent to participate.

Open Access This article is licensed under a Creative Commons Attribution 4.0 International License, which permits use, sharing, adaptation, distribution and reproduction in any medium or format, as long as you give appropriate credit to the original author(s) and the source, provide a link to the Creative Commons licence, and indicate if changes were made. The images or other third party material in this article are included in the article's Creative Commons licence, unless indicated otherwise in a credit line to the material. If material is not included in the article's Creative Commons licence and your intended use is not permitted by statutory regulation or exceeds the permitted use, you will need to obtain permission directly from the copyright holder. To view a copy of this licence, visit http://creativecommons.org/licenses/by/4.0/.

\section{References}

1. Ardern CL, Taylor NF, Feller JA, Webster KE (2013) A systematic review of the psychological factors associated with returning to sport following injury. Br J Sports Med 47:1120-1126

2. Bohu Y, Klouche S, Lefevre N, Webster K, Herman S (2015) Translation, cross-cultural adaptation and validation of the French version of the Anterior Cruciate Ligament-Return to Sport after Injury (ACL-RSI) scale. Knee Surg Sports Traumatol Arthrosc 23:1192-1196

3. Calder JD, Sexton SA, Pearce CJ (2010) Return to training and playing after posterior ankle arthroscopy for posterior impingement in elite professional soccer. Am J Sports Med 38:120-124

4. Caputo AM, Lee JY, Spritzer CE, Easley ME, DeOrio JK, Nunley JA, DeFrate LE (2009) In vivo kinematics of the tibiotalar joint after lateral ankle instability. Am J Sports Med 37:2241-2248

5. Clanton TO, Matheny LM, Jarvis HC, Jeronimus AB (2012) Return to play in athletes following ankle injuries. Sports Health 4:471-474

6. Feng S-M, Maffulli N, Ma C, Oliva F (2020) All-inside arthroscopic modified Broström-Gould procedure for chronic lateral 
ankle instability with and without anterior talofibular ligament remnant repair produced similar functional results. Knee Surg Sports Traumatol Arthrosc 29(8):2453-2461

7. Ferran NA, Maffulli N (2006) Epidemiology of sprains of the lateral ankle ligament complex. Foot Ankle Clin 11:659-662

8. Gerometta A, Klouche S, Herman S, Lefevre N, Bohu Y (2018) The Shoulder Instability-Return to Sport after Injury (SIRSI): a valid and reproducible scale to quantify psychological readiness to return to sport after traumatic shoulder instability. Knee Surg Sports Traumatol Arthrosc 26:203-211

9. Guillo S, Bauer T, Lee JW, Takao M, Kong SW, Stone JW, Mangone PG, Molloy A, Perera A, Pearce CJ, Michels F, Tourné Y, Ghorbani A, Calder J (2013) Consensus in chronic ankle instability: aetiology, assessment, surgical indications and place for arthroscopy. Orthop Traumatol Surg Res 99:S411-419

10. Guillo S, Odagiri H (2020) All-inside endoscopic Broström-Gould technique. Arthrosc Tech 9:e79-e84

11. Guillodo Y, Simon T, Le Goff A, Saraux A (2013) Interest of rehabilitation in healing and preventing recurrence of ankle sprains. Ann Phys Rehabil Med 56:503-514

12. Hølmer P, Søndergaard L, Konradsen L, Nielsen PT, Jørgensen LN (1994) Epidemiology of sprains in the lateral ankle and foot. Foot Ankle Int 15:72-74

13. Hunt KJ, Fuld RS, Sutphin BS, Pereira H, D’Hooghe P (2017) Return to sport following lateral ankle ligament repair is underreported: a systematic review. J ISAKOS 2:234-240

14. Hurley ET, Markus DH, Mannino BJ, Gonzalez-Lomas G, Alaia MJ, Campbell KA, Jazrawi LM, Strauss EJ (2021) Patients unable to return to play following medial patellofemoral ligament reconstructions demonstrate poor psychological readiness. Knee Surg Sports Traumatol Arthrosc 29:3834-3838

15. Kitaoka HB, Alexander IJ, Adelaar RS, Nunley JA, Myerson MS, Sanders M, Lutter LD (1997) Clinical rating systems for the ankle-hindfoot, midfoot, hallux, and lesser toes. Foot Ankle Int $18: 187-188$

16. Ko KR, Lee W-Y, Lee H, Park HS, Sung K-S (2020) Repair of only anterior talofibular ligament resulted in similar outcomes to those of repair of both anterior talofibular and calcaneofibular ligaments. Knee Surg Sports Traumatol Arthrosc 28:155-162

17. Lee K, Jegal H, Chung H, Park Y (2019) Return to play after modified broström operation for chronic ankle instability in elite athletes. Clin Orthop Surg 11:126-130

18. Maffulli N, Del Buono A, Maffulli GD, Oliva F, Testa V, Capasso G, Denaro V (2013) Isolated anterior talofibular ligament Broström repair for chronic lateral ankle instability: 9-year follow-up. Am J Sports Med 41:858-864

19. Mederake M, Hofmann UK, Ipach I (2021) Arthroscopic modified Broström operation versus open reconstruction with local periosteal flap in chronic ankle instability. Arch Orthop Trauma Surg. https://doi.org/10.1007/s00402-021-03949-2

20. Mokkink LB, Terwee CB, Patrick DL, Alonso J, Stratford PW, Knol DL, Bouter LM, de Vet HCW (2010) The COSMIN study reached international consensus on taxonomy, terminology, and definitions of measurement properties for health-related patientreported outcomes. J Clin Epidemiol 63:737-745

21. Nery C, Raduan F, Del Buono A, Asaumi ID, Cohen M, Maffulli N (2011) Arthroscopic-assisted Broström-Gould for chronic ankle instability: a long-term follow-up. Am J Sports Med 39:2381-2388

22. Park S, Kim T, Lee M, Park Y (2020) Absence of ATFL remnant does not affect the clinical outcomes of the modified broström operation for chronic ankle instability. Knee Surg Sports Traumatol Arthrosc 28:213-220

23. Podlog L, Heil J, Schulte S (2014) Psychosocial factors in sports injury rehabilitation and return to play. Phys Med Rehabil Clin N Am 25:915-930
24. ̌ezaninová J, Hrazdira L, Moc Králová D, Svoboda Z, Benaroya A (2018) Advanced conservative treatment of complete acute rupture of the lateral ankle ligaments: verifying by stabilometry. Foot Ankle Surg 24:65-70

25. van Rijn RM, van Os AG, Bernsen RMD, Luijsterburg PA, Koes BW, Bierma-Zeinstra SMA (2008) What is the clinical course of acute ankle sprains? A systematic literature review. Am J Med 121:324-331.e6

26. Roos EM, Brandsson S, Karlsson J (2001) Validation of the foot and ankle outcome score for ankle ligament reconstruction. Foot Ankle Int 22:788-794

27. Sadeqi M, Klouche S, Bohu Y, Herman S, Lefevre N, Gerometta A (2018) Progression of the psychological ACL-RSI score and return to sport after anterior cruciate ligament reconstruction: a prospective 2-year follow-up study from the French prospective anterior cruciate ligament reconstruction cohort study (FAST). Orthop J Sports Med 6:2325967118812819

28. Sigonney F, Lopes R, Bouché P-A, Kierszbaum E, Moslemi A, Anract P, Stein A, Hardy A (2020) The ankle ligament reconstruction-return to sport after injury (ALR-RSI) is a valid and reproducible scale to quantify psychological readiness before returning to sport after ankle ligament reconstruction. Knee Surg Sports Traumatol Arthrosc 28:4003-4010

29. Song Y, Li H, Sun C, Zhang J, Gui J, Guo Q, Song W, Duan X, Wang X, Wang X, Shi Z, Chinese Society of Sports Medicine, Hua Y, Tang K, Chen S (2019) Clinical guidelines for the surgical management of chronic lateral ankle instability: a consensus reached by systematic review of the available data. Orthop J Sports Med 7:2325967119873852

30. Sugimoto K, Takakura Y, Okahashi K, Samoto N, Kawate K, Iwai M (2009) Chondral injuries of the ankle with recurrent lateral instability: an arthroscopic study. J Bone Jt Surg Am 91:99-106

31. Terwee CB, Bot SDM, de Boer MR, van der Windt DAWM, Knol DL, Dekker J, Bouter LM, de Vet HCW (2007) Quality criteria were proposed for measurement properties of health status questionnaires. J Clin Epidemiol 60:34-42

32. Valderrabano V, Hintermann B, Horisberger M, Fung TS (2006) Ligamentous posttraumatic ankle osteoarthritis. Am J Sports Med 34:612-620

33. Webster KE, Feller JA, Lambros C (2008) Development and preliminary validation of a scale to measure the psychological impact of returning to sport following anterior cruciate ligament reconstruction surgery. Phys Ther Sport 9:9-15

34. White WJ, McCollum GA, Calder JDF (2016) Return to sport following acute lateral ligament repair of the ankle in professional athletes. Knee Surg Sports Traumatol Arthrosc 24:1124-1129

35. Wörner T, Thorborg K, Webster KE, Stålman A, Eek F (2021) Psychological readiness is related to return to sport following hip arthroscopy and can be assessed by the Hip-Return to Sport after Injury scale (Hip-RSI). Knee Surg Sports Traumatol Arthrosc 29:1353-1361

36. Yeung MS, Chan KM, So CH, Yuan WY (1994) An epidemiological survey on ankle sprain. Br J Sports Med 28:112-116

37. Zhou Y-F, Zhang Z-Z, Zhang H-Z, Li W-P, Shen H-Y, Song B (2021) All-inside arthroscopic modified Broström technique to repair anterior talofibular ligament provides a similar outcome compared with open Broström-Gould procedure. Arthroscopy $37: 268-279$

Publisher's Note Springer Nature remains neutral with regard to jurisdictional claims in published maps and institutional affiliations. 